\title{
TROIA: uma reflexão sobre cinema, história, tradição oral e sala de aula ${ }^{1}$
}

\author{
Matheus Mendanha Cruz*
}

\begin{abstract}
RESUMO: O presente texto é um esforço, sob o olhar da Didática da História de tendência alemã, para perceber a obra cinematográfica, mais especificamente o filme Troia, como uma organização de fatos que aponta para um sentido e o transmite aos espectadores. Desta forma, procuramos argumentar que a obra cinematográfica em questão pode ser utilizada como uma rica fonte em sala de aula, ajudando o estudante a perceber o papel da Indústria Cultural no nosso tempo e como a arte, através da tradição oral grega, também influenciava a Grécia Antiga, valorizando a percepção de que há por trás dos discursos sobre o passado interesses a serem defendidos.

PALAVRAS-CHAVE: Troia, Cultura Histórica, Tradição Oral Grega, Didática da História.
\end{abstract}

\section{Troy: a reflection about cinema, history, oral tradition and classroom}

ABSTRACT: The present text is an effort, upon from History's Didactics of german tendency, to perceive the cinematographic work, more specifically the film Troy, as an organization of facts that point for direction and conveys it to the spectator. In this way, we try to argue that the cinematographic work in question may be used as a rich font in the classroom, helping the student to perceive the role of Cultural Industry in our time and the art, through the Greek tradition oral, also influence ancient Greece, giving value to perception there is behind discourses about the past interests to be defended.

KEY WORDS: Troy, Historical Culture, Greek Tradition Oral, History Didactics.

\section{Troia: una reflexión sobre cine, historia, tradición oral y aula}

RESUMEN: El presente texto es un esfuerzo, a través la perspectiva de la Didáctica de la Historia de origen alemán, por percibir la obra cinematográfica, más concretamente la película Troia, como una organización de hechos que apunta a un significado y lo transmite al espectador. De esta forma, intentamos argumentar que la obra cinematográfica en cuestión puede ser utilizada como una rica fuente en el aula ayudando al alumno a comprender el papel de la Industria Cultural en nuestro tiempo y cómo el arte, a través de la tradición oral griega, también Influyó en la Antigua Grecia, valorando la percepción de que hay intereses que defender detrás de los discursos sobre el pasado.

PALABRAS LLAVE: Troy, Cultura histórica, Tradición Oral Griega, Didáctica de la Historia.

\footnotetext{
* Mestre em História pela Universidade Estadual de Ponta Grossa. Atualmente é professor na rede de educação básica de Santa Catarina. Contato: Escola de Ensino Básico Manoel Estevão Furtado: Rua Tenente Ary Rauen, 1319, São Cristóvão, CEP: 89370-000, Papanduva-SC, Brasil. E-mail: matheusmcruz@live.com. ORCID: https://orcid.org/0000-0003-2295-2689
} 
O primeiro ponto a ser abordado no texto que segue será a discussão acerca da Didática da História, ainda nesse tópico serão apresentados alguns aspectos da discussão acerca da Mediação Didática; no segundo tópico deste texto trabalharemos brevemente alguns pontos da discussão sobre Juventude e Estado; em seguida discutiremos alguns pontos da compreensão do cinema em sua relação com a História. Nesta parte nos deteremos um pouco mais por ser o eixo central da discussão do presente trabalho, tentaremos conjugar as reflexões feitas até então com o cinema e o seu papel dentro da Cultura Histórica.

Após a discussão sobre cinema e História refletiremos sobre a relação do cinema com as aulas de História de modo mais específico, sobre alguns limites e possiblidades. Com a base lançada pela discussão teórica nos ateremos à reflexão sobre as relações do filme Troia com a História e, logo depois, às possibilidades de utilizá-lo em aulas acerca da Grécia Antiga no Ensino Médio.

\section{Didática da História e Mediação Didática}

Para Klaus Bergmann² “o interesse fundamental da Didática da História consiste na investigação do significado da História no contexto social”. Esse campo do conhecimento pensa a circulação do conhecimento histórico na sociedade, tanto na formalidade quanto na informalidade, e a utilização desse na vida prática dos sujeitos.

A ação para compreender esse processo de circulação do conhecimento histórico é denominada de Reflexão Didática ${ }^{3}$ que pode ser dividida em três tarefas: Empírica compreender quais as informações históricas têm sido assimiladas e de onde elas vem; Reflexiva - refletir como se dão essas transmissões e porque são essas e não outras informações que ganham impulsão na circulação; e Normativa - normatizar aquilo que deve ser ensinado como conteúdo histórico ${ }^{4}$.

Outro conceito da Didática da História é o de Consciência Histórica. Rüsen ${ }^{5}$ explica que esse conceito se refere à atividade mental da memória histórica que se representa à interpretação da experiência do passada encaminhada a poder compreender as condições da atualidade e criar perspectivas de futuro.

Outro conceito que nos possibilita pensar a produção e circulação de conhecimento, dessa feita mais especificamente em sala de aula, é o de Mediação Didática ${ }^{6}$. Esse conceito pensa o processo de movimentação do conhecimento histórico e está muito próximo ao de Transposição Didática proposto por Chevellard ${ }^{7}$. 
Em linhas gerais, para Chevellard o conhecimento científico é construído na academia; depois passa por estruturas sociais e de Estado que discutem e filtram os saberes que devem ser ensinados. Esse âmbito de discussão é denominado de noosfera, podendo ser desde o Ministério da Educação às entidades deliberativas da comunidade escolar faz seleções e enfim o saber chega à sala de aula, onde o professor ainda faz mais ajustes para fazer a transposição aos alunos. Ou seja, aquele saber que foi produzido na academia não é o mesmo ensinado na educação básica. Sendo assim temos um saber na educação básica embasado, mas diverso do que a ciência produzida na academia. É importante destacar que existe interrelações entre as instâncias citadas acima, não é algo completamente rígido e hierarquizado.

Alice Lopes $^{8}$ não se detém a essa explicação e coloca na mesa de discussão mais um fator importante, que parece que Chevellard não ignora, mas também não valoriza: o aluno. A ideia de Lopes é que o processo de movimentação do conhecimento não vai apenas até o professor, mas até o aluno. Afinal, quando o professor leciona, cada aluno interpreta de uma maneira diferenciada o conteúdo que está em foco.

\section{Cinema e História}

O primeiro ponto a ser ressaltado na presente seção é o olhar que o historiador deve dar ao cinema como fonte histórica. Aqui colocamos em evidência a nossa filiação epistemológica que defende não haver diferenças de formação entre professores de História e historiadores ${ }^{9}$, pois todos os profissionais da história compartilham do método histórico, fazem pesquisa e publicam seus resultados, mantendo um olhar de historiador a tudo aquilo que está ao seu redor, buscando interpretar e reinterpretar o mundo que o cerca.

Uma das abordagens que é possível estabelecer para análise do historiador quando assume uma obra cinematográfica como fonte é a reflexão sobre a criação de sentido. $\mathrm{O}$ conceito de sentido para Rüsen ${ }^{10}$ é de um produto cultural que possibilita que o mundo em que o sujeito está inserido ganhe significado, ou seja, tem função explicativa, uma vez que torna possível a orientação, porque possibilita a compreensão do mundo e dos demais sujeitos.

A forma pela qual essa construção de sentido é feita internamente no sujeito e também apresentada a outros é a narração. Para Rüsen ${ }^{11}$ "narrar é um procedimento mental próprio à constituição humana de sentido [...] (e) um narrar é histórico quando se refere a acontecimentos reais do passado". É a estrutura narrativa que permite ordenar e dar sentido aos fatos do passado, possibilitando a influência do passado no presente. 
Essa organização do sentido acaba por privilegiar alguns aspectos/fatos em detrimento de outros, assim como na Operação Historiográfica descrita por Certeau ${ }^{12}$. Esse processo está completamente interligado ao meio de onde o historiador produz o seu discurso, Certeau ${ }^{13}$ afirma que "existe uma historicidade da história. Ela implica no movimento que liga uma prática interpretativa a uma prática social".

O cineasta, segundo Napolitano ${ }^{14}$, também faz escolhas e estas também devem ser analisadas, pois fazem parte da construção narrativa do sentido que vislumbra algum objetivo. Ismail Xavier ${ }^{15}$ deixa isso ainda mais claro quando afirma que o cinema é sempre um discurso, de certa forma ficcional, construído e controlado por uma fonte produtora.

Quando o diretor concebe um filme ele está construindo um sentido, apontando para alguma direção, sendo toda construção de sentido narrativa e toda narrativa objetivando a verdade $^{16}$, logo, todo filme tem uma intenção de verdade, ou efeito de verdade ${ }^{17}$. É sobre essa intenção de verdade que o historiador deve redobrar o seu olhar.

Napolitano $^{18}$ destaca que é esse efeito de verdade/realidade que desarma o telespectador, não permitindo que o mesmo questione os mais variados aspectos e fatos representados na obra cinematográfica. Sendo assim, acaba-se passando as ideias incutidas no filme sem filtros mais firmes, a pessoa que está em frente à tela consome as propostas da equipe idealizadora do filme sem perceber que o está fazendo.

Esse efeito de verdade/realidade é o que Ismail Xavier ${ }^{19}$ discute em seu texto com a denominação de Transparência. O conceito de transparência se coloca em oposição ao de opacidade. O primeiro refere-se à sensação que o telespectador sente de estar no próprio filme, ou seja, a linguagem cinematográfica está voltada para uma relação intensa do que assiste com a obra projetada, também é chamado de efeito-janela por passar a impressão do espectador de estar olhando aquela história por uma janela transparente. Já opacidade, valoriza mais o aparato técnico e textual.

Sendo uma produção é preciso compreender o contexto social no qual o filme e o diretor estão imersos. Ao analisar uma obra cinematográfica o historiador precisar se debruçar sobre quem a fez e as verdades que esta pretende passar para que, deste modo, possa compreender de maneira mais completa tal obra, não apenas aceitando a sua intenção de verdade como se a mesma fosse natural.

Para compreender a relação do contexto em que o filme é produzido com a afirmação anterior de que o filme não produz, mas perpetua e reforça determinadas ideias utilizaremos o conceito de Cultura Histórica descrito por Rüsen. 
“Cultura Histórica, é o campo em que os potenciais de racionalidade do pensamento histórico atuam na vida prática" ${ }^{20}$, ou seja, o campo da Cultura Histórica é a área em que os sujeitos colocam o conhecimento histórico, seus saberes sobre o passado, em prática no seu cotidiano.

É nessa área que se insere a produção e consumo de obras cinematográficas. Analisar um filme sob essa ótica possibilita questionar de maneira mais ampla e complexa aquilo que ele significa e a mensagem que ele veicula. Mesmo os filmes que não são ambientalizados em contextos tidos como históricos carregam conceitos e visões sobre o passado. Sendo assim, um dos papeis de um historiador ao fazer a análise de um determinado filme é compreender o entorno e os usos políticos, estéticos, artísticos, daquela obra, compreender os discursos transmitidos por aquela construção narrativa da história transformada em uma linguagem cinematográfica.

\section{Cinema e Sala de Aula}

No item anterior foram traçados alguns pontos teóricos acerca da relação do cinema com a ciência histórica. A linha até aqui construída dessa relação baseou-se mais na percepção e leitura do passado que o filme apresenta, do que nos fatos da própria história visíveis no filme. Desta maneira, é possível perceber que a obra cinematográfica fala mais do presente e de sua construção de sentido do que do próprio passado, mesmo naquelas ditas históricas.

Tendo claro essa base é interessante ressaltar, na relação cinema e aula de História, que o filme não deve ser tido apenas como uma ilustração, mas sim como texto gerador ${ }^{21}$. Essa postura permite a colocação da obra cinematográfica não como exemplo daquilo que já foi trabalhado com outra metodologia, mas oportuniza que o educando consiga, a partir daquela obra cinematográfica, ou parte dela, construir um saber acerca de determinado período histórico e sobre o presente em que foi concebida.

Esse modelo de abordagem beneficia o crescimento do aluno em relação a sua autonomia, pois educar para a vivência em sociedade é construir, em conjunto com os estudantes, as bases necessárias para a leitura do mundo que cerca esse sujeito no seu cotidiano $^{22}$. Quando o professor ensina ao educando a lançar questionamentos sobre uma fonte, no caso aqui uma fonte audiovisual, permite que o mesmo forme em si um olhar crítico sobre o mundo. 
Para que este processo se torne mais efetivo, Napolitano ${ }^{23}$ ressalta a necessidade de haver um roteiro prévio de questões. Nesse roteiro é aconselhável que constem perguntas acerca do filme, que levem o educando a ater-se a detalhes com o intuito de compreender a produção e a relação desta com o conteúdo histórico abordado. O ideal é que neste roteiro tenha a ficha técnica do filme para que o aluno pesquise sobre o processo de produção da obra, atores, diretores, vendagem, contexto, crítica.

A edição de filmes é uma ferramenta que pode ser muito útil para que haja um foco maior nas partes do filme que se referem especificamente ao conteúdo histórico que o professor pretende trabalhar. Essas edições podem ser pequenos cortes, bem como legendas ou detalhes destacados nas cenas que apontem no que ater a atenção.

Essas metodologias se tornam importantes para o uso do cinema de fato em sala de aula, porque a ausência dessa discussão teórica pode levar a utilização do filme apenas como "se as informações pudessem ser veiculadas do mesmo modo por meios de expressão diferentes. $\mathrm{O}$ filme [...] enfatiza ou confere materialidade, de modo atraente e divertido, àquilo que se lê no livro didático" ${ }^{24}$. Ações assim desconsideram completamente a chamada linguagem cinematográfica, além de cair num erro historiográfico de não problematizar a fonte e tê-la como reconstituição do acontecido tal como foi.

Um dos problemas centrais para o uso do cinema em sala de aula é a falta de tempo que os professores têm para se atualizarem, nem incentivo para tal. Alcides Ramos e Rosangela Patriota $^{25}$ reafirmam que a maioria dos professores sem [...]

[...] tempo para atualizar-se (em virtude da jornada de trabalho a que está submetido), sem dinheiro para comprar livros (em função dos baixos salários) e sem estímulo para enriquecer a sua formação (devido à falta de valorização social de seu saber), o professor vai pouco a pouco, se estagnando.

A outra limitação a ser destacada é a ausência de tempo e de estrutura da educação institucional. A realidade das escolas públicas, principalmente, é de falta de estrutura básica (cortinas, TVs ou projetores que funcionem perfeitamente). Para que a atividade alcance sucesso é importante que o professor prepare o ambiente e os aparelhos, planejando a aula de acordo com as possibilidades efetivas.

Ainda um fator importante de ser compreendido é que não é o uso do cinema em sala de aula que torna a técnica inovadora. Afinal não se torna uma atividade inovadora se o professor se mantém acrítico frente à fonte e passa para os alunos o filme, não como processo de construção de um determinado discurso, mas como recorte da realidade tal qual aconteceu, ou mesmo, como exemplo do que já foi lido no livro didático ${ }^{26}$. 
Mesmo com tantos desafios e limitações, ainda é possível relacionar cinema e aula de História. Pensar atividades que coloquem o filme como fonte a ser questionada é basilar para a compreensão dos estudantes das construções que os cercam constantemente e que, a maioria das vezes, são tidas como naturais. Sendo assim, a utilização de filmes em sala de aula serve a discussão acerca do momento que o mesmo foi concebido; sobre o presente, se caso ele estiver fazendo sucesso, pode levantar debates sobre os porquês disto; e também sobre algum conteúdo histórico que o professor consiga traçar relações junto aos alunos.

\section{Troia: Cinema, História e Tradição Oral}

Nossa reflexão acerca do filme Troia teve seu ponto inicial o contato com o texto de Renato Mocellin ${ }^{27}$. O livro em questão discute a relação entre cinema e aulas de História e seleciona quatro filmes, sob critério de serem os com temas históricos de maior bilheteria entre os anos de 1999 e 2009, para análise. As obras escolhidas foram Gladiador, Troia, Cruzada e $300^{28}$.

O texto produzido por Mocellin ${ }^{29}$ está consonante com a ideia de que uma obra cinematográfica reflete mais o presente do que o tempo que pretende representar. Sendo assim ele disseca o filme a partir da bilheteria, do estilo de marketing feita pelo filme, demonstrando pontos do contexto que o filme foi concebido e também ligando este contexto a aspectos do filme que se relacionam com tal. O autor também explica as tendências da Indústria Cultural e os meandros da cinegrafia hollywoodiana.

Mocellin ${ }^{30}$ em sua análise aponta que o filme Troia reflete o período de lançamento do mesmo, 2004, em que os EUA enfrentavam a chamada Guerra do Iraque. Dessa maneira a obra cinematográfica foi concebida em resposta às necessidades propagandísticas de guerra dos EUA, uma vez que valoriza os ideais de heroísmo de quem deixa sua terra natal, patriotismo, amor à família, a religião, etc. Em linhas gerais, é um filme pensado para justificar a guerra e lançar base ideológica para o esforço de guerra ${ }^{31}$.

Não é só Mocellin que apresenta uma avaliação negativa do filme, na verdade, a crítica em sites como Omelete, Cineplay, CineClick, Folha Ilustrada, também não se agradou com a obra também. Os principais apontamentos negativos são a pouca importância dada ao Cavalo de Troia; pouca contextualização da história, por exemplo, não se faz referência explicando a fraqueza de Aquiles; a ausência dos deuses; a estereotipação dos povos envolvidos. 
Embora concordemos com a análise feita por Mocellin no que tange a relação do filme com a denominada Guerra do Iraque, encontramos alguns pontos que valem a pena serem ressaltados quanto a sua crítica acerca do caráter mais histórico do filme. Aqui não se pretende apontar equívocos, mas oferecer a visão de um prisma diferente.

Mocellin $^{32}$ afirma que o filme não é fiel a Ilíada e não reconstitui nem o período Micênico, nem mesmo o período Homérico. Esta crítica do autor ocorre, e isso ele explica no decorrer do seu texto, pela maneira como os deuses, que na Ilíada tem papel central, são deixados em segundo plano; pelo escamoteamento das relações entre Aquiles e Pátroclo, que no filme são primos, mas que na Ilíada são amigos que, muito provavelmente, mantinham relações homo afetivas; pela presença no filme do conhecido Cavalo de Troia, que não é descrito na Ilíada e, sim, na Odisseia; e, também, porque o filme muda fatos importantes da Ilíada, por exemplo, na obra de Homero Menelau recupera Helena e volta à Esparta, já no filme ele é morto por Heitor; pela presença dos ideais de pátria e família monogâmica que estão presentes no filme, mas são configurações anacrônicas; pela presença de muralhas grandiosas e marinhas, inexistentes no período micênico.

Esses traços que o autor aponta são importantes e diferem, não resta dúvida, das sociedades micênicas e do período homérico, assim bem como da Ilíada. Entretanto a própria obra de Homero é cheia de incertezas. As acusações ao filme de não retratar de modo fiel as sociedades esbarra na própria natureza da Ilíada.

O período em que se aponta para o da guerra é o final do Micênico, em torno do século XII a.C e o da escrita da Ilíada é por volta do século VIII a.C. ${ }^{33}$. O período Micênico é marcado pelo domínio dos Aqueus, desenvolvimento de alguns reinos e domínio do bronze, sendo a organização política do período organizada em torno dos palácios. Essa fase termina e os estudiosos não chegaram a uma resposta definida de como isso ocorre ${ }^{34}$. O período que se sucede é conhecido como Homérico ou Idade Obscura ou ainda Idade das Trevas ${ }^{35}$, devido à ausência de informações, principalmente pela ausência de escrita que marca esse espaço de tempo que vai até os entornos do século VIII a. $C^{36}$. Após o período Homérico segue-se o período Arcaico, que é marcado pelo ressurgimento da escrita e o surgimento da Pólis ${ }^{37}$.

Para que possamos compreender melhor a discussão acerca da Ilíada, e do próprio filme Troia, é preciso olhar para o autor da obra grega: Homero. É tão complexa a reflexão sobre o referido período que até sobre a existência e a autoria de Homero pairam dúvidas, tornando-se difícil até mesmo associar os poemas ao período micênico 
Gustavo Oliveira ${ }^{38}$ indica que, embora existam muitas discussões sobre a qual período pertença os poemas atribuídos a Homero, o mais relevante é compreendê-los como exemplares da tradição oral épica. O texto de Camila Zanon ${ }^{39}$ aponta para a forte influência da tradição oral sobre os poemas, entretanto ressalta duas teorias existentes acerca de Homero. Na primeira, Homero é um termo que expressa uma determinada coletividade; na segunda, Homero é o sujeito que dita, e não escreve, a um terceiro as histórias.

Para deixar ainda mais complexo, os autores só começam a assinar suas obras no século VIII a.C. ${ }^{40}$, por isso não é possível rastrear a sua origem, nem mesmo se tem informações sobre o processo inicial da composição desta obra ${ }^{41}$.

Ainda não se conseguiu chegar a uma conclusão efetiva de quem foi Homero, mas o que há um consenso é de que a Ilíada, como outros poemas, eram transmitidos dentro de uma tradição oral durante o período denominado Idade Obscura e que a datação do poema em sua versão escrita está por volta do século VIII.

Essa tradição oral se destaca devido à ausência da escrita na Idade das Trevas, ela refere-se à criação de poemas e a perpetuação destes de maneira oral. Gustavo Oliveira (2008, p.5) ressalta a ideia de performance, ou seja, "o poeta que canta não é apenas um veículo para a tradição, pois também a cria ao cantar, uma vez que é um poeta criativo. Um mero recitador não é um poeta oral".

Esse aspecto de criação da poesia do período é confirmado por outros autores. Fernando dos Santos ${ }^{42}$ explica que poesia vem do grego e significa criar, moldar e que era tida como inspiração dos deuses. Maria Rocha Pereira ${ }^{43}$ afirma que o aedo tem por função deleitar quem o ouve e que para isso "há que celebrar temas novos, atuais", ou seja, "o aedo é capaz de improvisar sobre o regresso dos heróis [...] ou ainda sobre a tomada de Troia e a história do cavalo de pau". Conjugando o pensamento desses autores, é possível notar quão flexível eram os enredos das histórias, esses podendo ser mudados pela força criativa do aedo cada vez que um novo contador invocava a história, afinal "cada performance é uma recriação" 44 .

Seguindo essa linha de pensamento o próprio Mocellin ${ }^{45}$ aponta para o compromisso de Homero não com a história ou com os fatos ocorridos, mas com a poesia, a literatura. Para corroborar essa tendência destaca-se que nem mesmo foram encontradas evidências da existência da cidade de Troia como está descrita na Ilíada ${ }^{46}$.

Essas poesias tinham função de educar ${ }^{47}$ e recordar ${ }^{48}$. No caso dos poemas homéricos ganharam força justamente no período da Idade das Trevas, afinal são esses poemas que 
carregaram a preservação dos valores de coragem e a memória de tempos gloriosos no passado em tempos considerados de retrocesso cultural, social e econômico ${ }^{49}$.

Homero, devido a esses poemas, passa a ser considerado o grande educador da Grécia, lançando a base, através dos personagens de suas histórias, da bravura, justiça, sabedoria e honestidade que definiram a identidade grega no período arcaico ${ }^{50}$.

Dentre os ideais presentes nas obras homéricas, destaca-se a ideia do herói que morre de maneira bela, sendo erguido a um estado de glória, permanecendo vivo ainda que morto. Este ideal inspira, por exemplo, a memória ateniense ${ }^{51}$. Juliana Murari e José Pereira Melo ${ }^{52}$ corroboram essa ideia afirmando que:

Na Ilíada, a figura do guerreiro é central. O comportamento do homem não está voltado para a vida pública, em sociedade, mas para suas atitudes na guerra. A figura do herói nesses poemas está sempre inserida em alguma batalha, e o que determina suas virtudes é sua bravura, lealdade, coragem e espírito de liderança.

Refletindo sobre os pontos aqui expostos acerca da Ilíada, seguimos a ideia de Gustavo Oliveira $^{53}$, defensor de que o olhar lançado sobre os poemas homéricos não deve ter o objetivo de reconstruir as cidades e sociedades que eles narram, pelo contrário, deve estar voltado a compreender os valores ideais transmitidos por eles.

Partindo desse pressuposto, defendemos uma visão acerca do filme Troia diferente da maioria da crítica. Mocellin, como visto anteriormente, critica fortemente o filme por não seguir a Ilíada, por não reproduzir nem as sociedades micênicas, nem a homérica e tratar de conceitos anacrônicos, já nosso objetivo será de nos atermos mais a relevância da tradição oral.

\section{Troia: Cinema, História e Sala de Aula}

Marc Ferro ${ }^{54}$ em seu texto demonstra que o cinema em sua gênese foi tido como cultura inferior, como obra sem identidade, onde há censura, fiscalizando-a sempre. Alcides $\operatorname{Ramos}^{55}$ também observa este fator em seu texto quando se refere à historiografia que demora, e ainda tem reservas, em aceitar as produções cinematográficas como discursos que podem ser abordados com métodos próprios e, sim, serem trabalhados como fontes históricas.

Marc Ferro fortalece essa tendência de romper com a supervalorização da cultura escrita quando afirma que é necessário não procurar somente nos filmes as confirmações daquilo que já está posto na tradição escrita. 
Marcel Amorim ${ }^{56}$ critica os que menosprezam o filme por este não ser fiel ao livro, afirmando que este tipo de posicionamento e fruto de preconceito que se perpetua colocando a arte cinematográfica como inferior a cultura escrita. Esta é uma das bases para a proposta que aqui será apresentada, proposta essa que não pretende comparar a Ilíada e o filme Troia, mas relacioná-los como leitura de uma determinada sociedade.

Levando em conta essa valorização dos filmes, tomando-os como fontes históricas e levando em conta todo processo metodológico de análise de fontes, principalmente a crítica que deve ser feita analisando o contexto de produção original do objeto de estudo, sugerimos uma valorização da produção Troia em sala de aula que valorize a visão do início dos anos 2000 sobre assuntos como guerra, homossexualidade, bem como a relação com a religião.

Ao apresentar o filme, ou uma seleção de cenas, e lançando questionamentos aos alunos para que eles possam refletir e se posicionarem o professor ensina além do conteúdo, também ensina a pensar historicamente. Essa competência do pensamento histórico é bastante valorizada por Bodo Von Borries ${ }^{57}$, uma vez que o sujeito que sabe os fatos e acontecimentos do passado não necessariamente consegue relacioná-los ao presente para compreender a sua vida prática.

Esse pensar historicamente está relacionado com a competência narrativa que é a responsável por permitir que o sujeito organize esses fatos do passado de forma que gere sentido e, desta maneira, oriente a vida prática no presente.

Quando se coloca a obra cinematográfica, no caso Troia, como texto gerador para uma aula acerca do período homérico, mesmo sobre o período do surgimento das polis gregas, e se coloca questionamentos sobre o filme que levem o educando a pensar no processo formador de discursos, como o cinema e a poesia clássica, é possível chegar à discussão sobre a importância da tradição oral para os gregos antigos. Para tal é necessário ressaltar a dinâmica da oralidade na antiguidade grega, em especial a sua importância para construção/manutenção de identidades.

Propomos aqui o desenrolar das atividades seguindo como linha principal de pensamento e de discussão a Tradição Oral, porque é possível considerar o cinema também como uma cultura oral ${ }^{58}$, em que histórias são organizadas para comunicar uma mensagem, mesmo que ela não apareça de forma direta. Sendo assim se torna possível compreender como a arte atua na atualidade e na antiguidade, permitindo que o jovem desenvolva sua leitura de forma mais aprofundada e crítica daquilo que lhe rodeia. 
Partir da análise do filme valorizando o presente e pensando as tensões militares que envolvem a política estadunidense, é parte do processo proposto por Rüsen segundo o qual o educando só aprende quando a abordagem parte de "experiências de ações relevantes do presente"

\section{Considerações Finais}

A proposta que apresentamos nesse artigo visou refletir sobre o cinema, mais especificamente sobre o filme Troia, e a sua relação com a construção dos discursos históricos. Pensar Troia como fruto do meio em que foi produzido, assim bem como a Ilíada também o foi, é imprescindível para auxiliar aos alunos de ensino médio na construção da sua autonomia e leitura de mundo, assim bem como o processo histórico de construção de sentido.

Todo esse processo está afinado com a crítica que Bodo Von Borries ${ }^{60}$, segundo a qual não se pode valorizar apenas o conteúdo, porque o ensino de História deve servir para além de conhecer sobre o passado e deve estar ligado com a orientação da vida prática do presente.

No processo de construção do artigo é possível observar o conceito de Cultura Histórica para compreender posicionamento do diretor e produtores do filme quanto ao passado e também como os alunos reagem à obra cinematográfica. A Consciência Histórica está implícita, pois é quem organiza o passado, dando-lhe sentido, dando assim o substrato para as ações e posicionamentos da Cultura Histórica. A Reflexão Didática é o conceito base para compreender o desenrolar das ideias apresentadas aqui, pois é essa ação que é feita ao se olhar ao redor e buscar compreender a relação do passado com a vida prática do presente.

A reflexão sobre Mediação Didática permite que se perceba que os conteúdos e conceitos ensinados, tanto no filme como em sala de aula, são saberes diferentes e, sendo assim, devem ser valorizados como tal. Além disso, coloca-nos frente a questão do envolvimento do aluno, compreender como este jovem entende aquilo que está sendo passado pelo cinema ou nas aulas de História. Esse esforço tem muito da Cultura Histórica, Consciência Histórica e também de compreender sobre a juventude que está presente nas escolas.

Por fim, pensar esses conceitos juntos permite uma reflexão mais próxima do que é encarado no cotidiano. Ainda mais na contemporaneidade em que os meios de comunicação de massa têm adquirido cada vez mais força. Compreender os seus produtos como discursos e se debruçar sobre eles para uma reflexão mais analítica é imprescindível para localizar-se no próprio presente e ser sujeito ativo do mesmo. 


\section{Notas}

${ }^{1}$ Quero aqui expressar meus agradecimentos à professora Rosangela Petuba, da Universidade Estadual de Ponta
Grossa, pelas discussões acerca da relação de História e Cinema, que muito contribuíram para a construção do presente artigo.

${ }^{2}$ BERGMANN, K. A História na Reflexão Didática. Revista Brasileira de História, São Paulo, v. 9, n. 19, p. 29 42, 1989/1990, p.31.

${ }^{3}$ BERGMANN, K. Op. Cit., 1989/1990, p.29.

${ }^{4}$ BERGMANN, K. Op. Cit., 1989/1990, p.30-31

${ }^{5}$ RÜSEN, J. El libro de texto ideal: Reflexiones entorno a los medios para guiar les clases de historia. Iber: Didáctica de las ciencias sociales, geografía e historia, v. 12, p. 79-94, 1997, p.81.

${ }^{6}$ LOPES, A. R. C. Processo de Mediação (ou Transposição) Didática. In: Ciência e Cotidiano. Rio de Janeiro: EDUERJ, 1999. p. 201-220.

${ }^{7}$ CHEVELLARD, Y. La Transposición Didáctica: Del Saber Sabio al Saber Enseñado. $3^{\mathrm{a}}$. ed. Argentina: Aique, 1996.

${ }^{8}$ LOPES, A. R. C. Op. Cit. 1999.

${ }^{9}$ CERRI, L. F. O Historiador na Reflexão Didática. História \& Ensino, Londrina, v. 19, n. 1, p. 27-47, jan./jun. 2013, p.36.

${ }^{10}$ RÜSEN, J. Teoria da História: Uma teoria da história como ciência. Tradução de Estevão C. de Rezende Martins. Curitiba: Editora UFPR, 2015, p.41-42.

${ }^{11}$ RÜSEN, J. Op. Cit. 2015, p.53-54.

${ }^{12}$ CERTEAU, M. D. Operação Historiográfica. In: A Escrita da História. Tradução de Maria de Lourdes Menezes. 2a . ed. Rio de Janeiro: Editora Forense Universitária, 2000.

${ }^{13}$ CERTEAU, M. D. Op. Cit. 2000, p.33.

${ }^{14}$ NAPOLITANO, Marcos. Como usar o cinema na sala de aula. São Paulo: Contexto, 2010.

${ }^{15}$ XAVIER, I. O Discurso Cinematográfico: a opacidade e a transparência. $3^{\text {a }}$. ed. São Paulo: Paz e Terra, 2005 , p. 14

${ }^{16}$ RÜSEN, J. Op. Cit. 2015, p. 61.

${ }^{17}$ RAMOS, A. F. Cinema e História: Do filme como documento à escritura fílmica da Hitória. In: THOMAS, M. C.; PATRIOTA (ORG.), R. Política, Cultura e Movimentos Sociais. Uberlândia: Universidade Federal de Uberlândia, 2001, p.26.

${ }^{18}$ NAPOLITANO, M. Op. Cit. 2010.

${ }^{19}$ XAVIER, I. Op. Cit. 2005, p.8.

${ }^{20}$ RÜSEN, J. História Viva: teoria da História: formas e funções do conhecimento histórico. Brasília: Editora da Universidade de Brasília, 2010ª p.121.

${ }^{21}$ NAPOLITANO, M. Op. Cit. 2010.

${ }^{22}$ FREIRE, P. Pedagogia da Autonomia: Saberes Necessários à Prática Educativa. 12a . ed. São Paulo: Paz e Terra, 1996.

${ }^{23}$ NAPOLITANO, M. Op. Cit. 2010.

${ }^{24}$ RAMOS, A. F.; PATRIOTA, R. Cinema-Teatro-Ensino de História: Proposições temáticas e apontamentos metodológicos. In: CARDOSO, H. H.; MACHADO, M. C. T. História: narrativas plurais, múltiplas linguagens. Uberlândia: EDUFU, 2005, p.180-181.

${ }^{25}$ RAMOS, A. F.; PATRIOTA, R. Op. Cit. 2005, p.178-179.

${ }^{26}$ RAMOS, A. F.; PATRIOTA, R. Op. Cit. 2005, p.180-181.

${ }^{27}$ MOCELLIN, R. História e Cinema: educação para as mídias. São Paulo - SP: Editora do Brasil, 2009.

${ }^{28}$ MOCELLIN, R. Op. Cit. 2009, p.13-14.

${ }^{29}$ MOCELLIN, R. Op. Cit. 2009.

${ }^{30}$ MOCELLIN, R. Op. Cit. 2009, p.55-56.

${ }^{31}$ MOCELLIN, R. Op. Cit. 2009, p. 51-58. 
${ }_{32}^{32}$ MOCELLIN, R. Op. Cit. 2009, p.58.

${ }^{33}$ ZANON, C. A. A Ilíada de Homero e a Arqueologia. São Paulo: Universide de São Paulo - USP, 2008, p.160, 162.

${ }^{34}$ GABRECHT, A. P. Poder e o Sagrado na Idade das Trevas: A configuração simbólica da realeza homérica. Vitória - ES: Universidade Federal do Espírito Santo, 2006, p.25, 27, 35.

${ }_{35}$ Essa nomenclatura é bastante centrada nas fontes escritas, o que vem sendo superado pelos estudos arqueológicos.

${ }^{36}$ GABRECHT, A. P. Op. Cit. 2006, p.25, 38.

${ }^{37}$ FLORENZANO, M. B. B. A origem da pólis: os caminhos da Arqueologia. In: CORNELLI, G.; (ORG.) Representações da Cidade Antiga: categorias históricas e discursos filosóficos. Coimbra: Centro de Estudos Clássicos e Humanísticos, 2010, p.40.

${ }^{38}$ OLIVEIRA, G. História de Homero: um balanço das propostas de datação dos poemas homéricos. Revista História e Cultura, Franca-SP, v.1, n.2, p.126-147, 2012, p.140.

${ }^{39}$ ZANON, C. A. Op. Cit. 2008, p.160-161.

${ }^{40}$ SANTOS, F. B. D. O canto dos helenos: poesia e performance. Revista Brasileira de Estudos Clássicos, v. 25, n. $1 / 2,2012$, p.240.

${ }^{41}$ OLIVEIRA, G. J. D. Os poemas homéricos e a tradição épica oral da qual fazem parte: uma proposta alternativa para datação e utilização da Ilíada e da Odisséia como fontes históricas. XXVII Simpósio Nacional de História. Natal - RN: ANPUH Brasil. 2013, p.2

${ }^{42}$ SANTOS, F. B. D. Op. Cit. 2012, p. 232-233.

${ }^{43}$ PEREIRA, M. H. R. O Conceito de Poesia na Grécia Antiga. Humanitas, v. XIII-XIV, p. 336-357, 1961/1962, p.339-340.

${ }^{44}$ OLIVEIRA, G. J. D. Homero: oralidade, tradição e história. Revista eletrônica de crítica e teoria de literaturas, Porto Alegre, v. 4, n. 1, 2008, p.6.

${ }^{45}$ MOCELLIN, R. Op. Cit. 2009, p.55.

${ }^{46}$ MOCELLIN, R. Op. Cit. 2009, p.52-53.

${ }^{47}$ MURARI, J. C.; PEREIRA MELO, J. J. A Problemática das Epopeias Homéricas: Uma reflexão sobre as possibilidades de sua abordagem nas pesquisas históricas. VIII Jornada de Estudos Antigos e Medievais / I Jornada Internacional de Estudos Antigos e Medievais. Maringá: [s.n.]. 2010, p. 1

${ }^{48}$ OLIVEIRA, G. Op. Cit. 2008, p. 14.

${ }^{49}$ MURARI, J. C.; PEREIRA MELO, J. J. A Poesia Homérica como Instrumento Educador Fundamental na Grécia Antiga. Seminário de Pesquisa do PPE. Maringá - PR: Universide Estadual do Paraná. 2009, p.4.

${ }^{50}$ MURARI, J. C.; PEREIRA MELO, J. J. Op. Cit. 2009, p.5.

${ }^{51}$ GRILLO, J. G. C. A Guerra de Troia no Imaginário Ateniense: Sua representação nos vasos áticos dos século VI-V a.C. PHOÎNIX, Rio de Janeiro, v. 16, n. 1, p. 32-49, 2010, p.34-35.

${ }^{52}$ MURARI, J. C.; PEREIRA MELO, J. J. A Problemática das Epopeias Homéricas: Uma reflexão sobre as possibilidades de sua abordagem nas pesquisas históricas. VIII Jornada de Estudos Antigos e Medievais / I Jornada Internacional de Estudos Antigos e Medievais. Maringá: [s.n.]. 2010, p.8.

${ }^{53}$ OLIVEIRA, G. Op. Cit. 2008, p.20.

${ }^{54}$ FERRO, M. O Filme: uma contra-análise da sociedade? In: (ORG.) NORA, P. História: Novos Objetos. Rio de Janeiro: Francisco Alvez, 1975.

${ }^{55}$ RAMOS, A. F. Cinema e História: Do filme como documento à escritura fílmica da Hitória. In: THOMAS, M. C.; PATRIOTA (ORG.), R. Política, Cultura e Movimentos Sociais. Uberlândia: Universidade Federal de Uberlândia, 2001.

${ }^{56}$ AMORIM, M. Á. D. Ver um livro, ler um filme: Sobre a tradução/adaptação de obras literárias para o cinema como prática de leitura. XIV Congresso Nacional de Linguística e Filologia. Rio de Janeiro: [s.n.]. 2010, p.1737.

${ }^{57}$ BORRIES, B. V. Competência do pensamento histórico, domínio de um panorama histórico ou conhecimento do cânone histórico. Educar em Revista, Curitiba, v. 60, p. 171-196, abr./jun. 2016, p.177.

${ }^{58}$ ALMEIDA, M. J. D. Imagens e Sons: A Nova Cultura Oral. São Paulo: Cortez, 1994.

${ }^{59}$ RÜSEN, J. Aprendizado Histórico. In: SCHMIDT, M. A.; BARCA, I.; MARTINS (ORG.), E. D. R. Jörn Rüsen e o ensino de História. Curitiba: Editora UFPR, 2010b, p.44.

${ }^{60}$ BORRIES, B. Op. Cit. 2016.

\section{Referências}


ALMEIDA, M. J. D. Imagens e Sons: A Nova Cultura Oral. São Paulo: Cortez, 1994.

AMORIM, M. Á. D. Ver um livro, ler um filme: Sobre a tradução/adaptação de obras literárias para o cinema como prática de leitura. XIV Congresso Nacional de Linguística e Filologia. Rio de Janeiro: [s.n.]. 2010. p. 1725-1739.

BERGMANN, K. A História na Reflexão Didática. Revista Brasileira de História, São Paulo, v. 9, n. 19, p. 29-42, 1989/1990.

BORRIES, B. V. Competência do pensamento histórico, domínio de um panorama histórico ou conhecimento do cânone histórico. Educar em Revista, Curitiba, v. 60, p. 171-196, abr./jun. 2016.

CERRI, L. F. O Historiador na Reflexão Didática. História \& Ensino, Londrina, v. 19, n. 1, p. 27-47, jan./jun. 2013.

CERTEAU, M. D. Operação Historiográfica. In: A Escrita da História.

Tradução de Maria de Lourdes Menezes. $2^{\mathrm{a}}$. ed. Rio de Janeiro: Editora Forense Universitária, 2000 .

CHEVELlARD, Y. La Transposición Didáctica: Del Saber Sabio al Saber Enseñado. $3^{\mathrm{a}}$. ed. Argentina: Aique, 1996.

FERRO, M. O Filme: uma contra-análise da sociedade? In: (ORG.) NORA, P. História: Novos Objetos. Rio de Janeiro: Francisco Alvez, 1975.

FLORENZANO, M. B. B. A origem da pólis: os caminhos da Arqueologia. In: CORNELLI, G.; (ORG.) Representações da Cidade Antiga: categorias históricas e discursos filosóficos. Coimbra: Centro de Estudos Clássicos e Humanísticos, 2010. p. 39-49.

FREIRE, P. Pedagogia da Autonomia: Saberes Necessários à Prática Educativa. 12a . ed. São Paulo: Paz e Terra, 1996.

GABRECHT, A. P. Poder e o Sagrado na Idade das Trevas: A configuração simbólica da realeza homérica. Vitória - ES: Universidade Federal do Espírito Santo, 2006.

GRILLO, J. G. C. A Guerra de Troia no Imaginário Ateniense: Sua representação nos vasos áticos dos século VI-V a.C. PHOÎNIX, Rio de Janeiro, v. 16, n. 1, p. 32-49, 2010.

LOPES, A. R. C. Processo de Mediação (ou Transposição) Didática. In:

Conhecimento Escolar: Ciência e Cotidiano. Rio de Janeiro: EDUERJ, 1999. p. 201-220.

MOCELLIN, R. História e Cinema: educação para as mídias. São Paulo - SP: Editora do Brasil, 2009. 
MURARI, J. C.; PEREIRA MELO, J. J. A Poesia Homérica como Instrumento Educador Fundamental na Grécia Antiga. Seminário de Pesquisa do PPE. Maringá - PR: Universide Estadual do Paraná. 2009.

MURARI, J. C.; PEREIRA MElO, J. J. A Problemática das Epopeias Homéricas: Uma reflexão sobre as possibilidades de sua abordagem nas pesquisas históricas. VIII Jornada de Estudos Antigos e Medievais / I Jornada Internacional de Estudos Antigos e Medievais. Maringá: [s.n.]. 2010.

NAPOLITANO, Marcos. Como usar o cinema na sala de aula. São Paulo: Contexto, 2010.

OLIVEIRA, G. J. D. Homero: oralidade, tradição e história. Revista eletrônica de crítica e teoria de literaturas, Porto Alegre, v. 4, n. 1, 2008.

OLIVEIRA, G. História de Homero: um balanço das propostas de datação dos poemas homéricos. Revista História e Cultura, Franca-SP, v.1, n.2, p.126-147, 2012.

OLIVEIRA, G. J. D. Os poemas homéricos e a tradição épica oral da qual fazem parte: uma proposta alternativa para datação e utilização da Ilíada e da Odisséia como fontes históricas. XXVII Simpósio Nacional de História. Natal - RN: ANPUH Brasil. 2013.

PEREIRA, M. H. R. O Conceito de Poesia na Grécia Antiga. Humanitas, v. XIII-XIV, p. 336-357, 1961/1962.

RAMOS, A. F. Cinema e História: Do filme como documento à escritura fílmica da Hitória. In: THOMAS, M. C.; PATRIOTA (ORG.), R. Política, Cultura e Movimentos Sociais. Uberlândia: Universidade Federal de Uberlândia, 2001. p. 7-26.

RAMOS, A. F.; PATRIOTA, R. Cinema-Teatro-Ensino de História: Proposições temáticas e apontamentos metodológicos. In: CARDOSO, H. H.; MACHADO, M. C. T. História: narrativas plurais, múltiplas linguagens. Uberlândia: EDUFU, 2005. p. 177-196.

RÜSEN, J. El libro de texto ideal: Reflexiones entorno a los medios para guiar les clases de historia. Iber: Didáctica de las ciencias sociales, geografía e historia, v. 12, p. 79-94, 1997.

RÜSEN, J. História Viva: teoria da História: formas e funções do conhecimento histórico. Brasília: Editora da Universidade de Brasília, 2010a.

RÜSEN, J. Aprendizado Histórico. In: SCHMIDT, M. A.; BARCA, I.; MARTINS (ORG.), E. D. R. Jörn Rüsen e o ensino de História. Curitiba: Editora UFPR, 2010b. p. 41-49.

RÜSEN, J. Teoria da História: Uma teoria da história como ciência. Tradução de Estevão C. de Rezende Martins. Curitiba: Editora UFPR, 2015.

SANTOS, F. B. D. O canto dos helenos: poesia e performance. Revista Brasileira de Estudos Clássicos, v. 25, n. 1/2, 2012. 
SILVA, E. Cinema e ensino de história: a Idade Média em O nome da Rosa de Jean-Jacques Annaud. O olho da História, Salvador, v. 17, Dezembro 2011.

TROIA. Direção: Wolfgang Petersen. Produção: Colin Wilson; Wolfgang Petersen e Diana Rathbun. [S.1.]: WARNER BROS. 2004.

XAVIER, I. O Discurso Cinematográfico: a opacidade e a transparência. $3^{\text {a }}$. ed. São Paulo: Paz e Terra, 2005.

ZANON, C. A. A Ilíada de Homero e a Arqueologia. São Paulo: Universide de São Paulo USP, 2008. 